\title{
Boolean Algebra for Xor-Gates
}

\author{
Lianly Rompis* \\ Electrical Engineering Department, UniversitasKatolik De la Salle, Manado, Indonesia \\ *Corresponding author: lrompis@ unikadelasalle.ac.id
}

Received December 26, 2012; Revised February 04, 2013; Accepted February 28, 2013

\begin{abstract}
Rules and laws of Boolean algebra are very essential for the simplification of a long and complex logic equation. Applying the Boolean algebra basic concept, such a kind of logic equation could be simplified in a more simple and efficient form.

Mainly, the standard rules of Boolean algebra are given in operator '+' and ' $x$ ', based on the AND and OR logic gates equations. For some logic designs, it is commonly that logic problems are writtenin terms of XOR format.

This paper tries to conduct something different. It will analyze, describe, and derive Boolean algebra rules related to logic equations using exclusive-or (XOR) logic gate.
\end{abstract}

Keywords: Boolean algebra, Xor-Gate, logic gates

\section{Introduction}

In a major way, Boolean algebra differs from mathematics algebra. Boolean constants and variables are allowed to have only two logic values, 0 or 1 , giving an output of these two possibilities [1,2,3].

Boolean Algebra is the algebra for digital signals. Standard rules and laws of th is unique Algebra are derived from logic gates characteristics (AND-gate and ORgate).Few characteristics are shown in Figure 1 and Figure 2 .

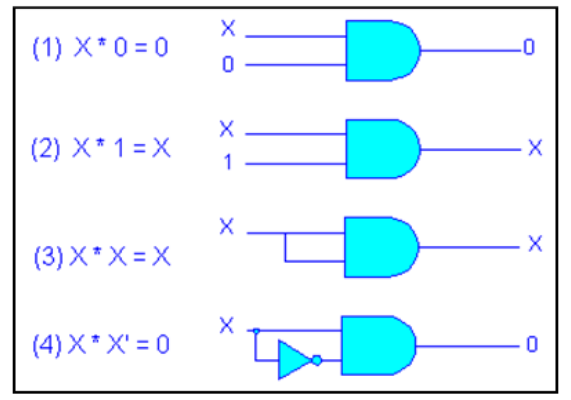

Figure 1. Basic Multiplications for Boolean Algebra (characteristic of AND-gate)

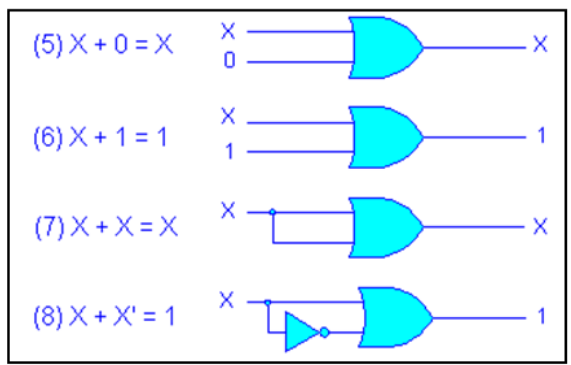

Figure 2. Basic Additions for Boolean Algebra (characteristic of ORgate)
From these basic rules, other rules are being derived as follows:

$$
\begin{gathered}
\overline{\bar{X}}=X \\
A+A B=A \\
A+\bar{A} B=A+B \\
(A+B)(A+C)=A+B C
\end{gathered}
$$

Beside rules, standard laws also have been set up for Boolean Algebra that generally use the same principles of mathe matics algebra $[2,4,5]$.

A. Commutative Law:

$$
\begin{gathered}
\text { A.B }=\text { B.A } \\
\mathrm{A}+\mathrm{B}=\mathrm{B}+\mathrm{A}
\end{gathered}
$$

B. Associative Law:

$$
\begin{aligned}
A \cdot(B C) & =(A B) \cdot C \\
A+(B+C) & =(A+B)+C
\end{aligned}
$$

C. Distributive Law:

$$
\text { A. }(\mathrm{B}+\mathrm{C})=\mathrm{AB}+\mathrm{AC}
$$

Those rules and laws will offer you a great help when dealing with a complicated logic equations that need to be worked out.

\section{Aims of Study}

This paper is trying to derive rules of Boolean Algebra related to a logic equation of an exclusive-or (XOR) gate. There is a hope that this method will be useful for students, lecturers, and anyone that are interested in learning number system, or to whom that are taking subject re lated to computer or dig ital system. 


\section{Research Method}

To derive the rules of Boolean Algebra related to an XOR gate, I take the basic point of standard rules and substitutes the standard rules with an XOR gate function

\section{Discussion and Results}

XOR-gate is a basic logic gate in dig ital system that use the combination of AND and OR gates.
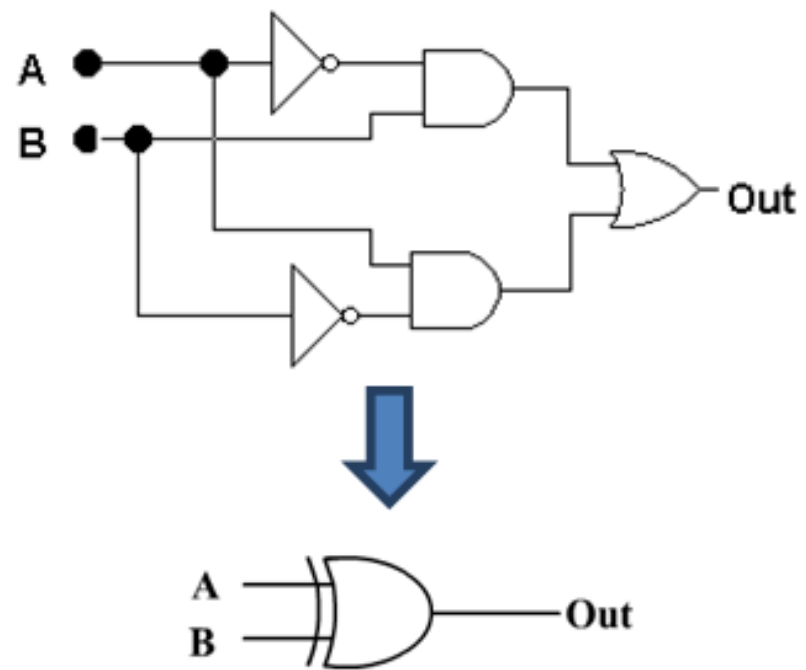

Figure 3. Logic Symbol of XOR Gate

The characteristic of XOR gate is given as follows: $[1,2,3]$

Table 1. XO R-Gate Truth Table

\begin{tabular}{|c|c|c|}
\hline A & B & Out \\
\hline 0 & 0 & 0 \\
\hline 0 & 1 & 1 \\
\hline 1 & 0 & 1 \\
\hline 1 & 1 & 0 \\
\hline
\end{tabular}

If the number of logic $1 \mathrm{~s}$ is Odd, the output will be 1 , otherwise it will be 0 .

Using the characteristic of XOR gate, substitutes the standard rules of Boolean Algebra with this function.If needed, apply Boolean Algebra laws.

$$
\begin{gathered}
X \oplus 0=\bar{X} .0+X . \overline{0} \\
=\bar{X} .0+X .1=\mathbf{X} \\
X \oplus 1=\bar{X} . .1+X . \overline{1} \\
=\bar{X} .1+X .0=\overline{\mathbf{X}} \\
X \oplus X=\bar{X} \cdot X+X . \bar{X} \\
=0+0=0 \\
\bar{X} \oplus X=X X+\bar{X} \cdot \bar{X}=1 \\
\bar{X} \oplus \bar{X}=X \bar{X}+\bar{X} \cdot X=0
\end{gathered}
$$

$$
\begin{aligned}
& A \oplus A B=\bar{A} \cdot A B+A \cdot \overline{\overline{A B}} \\
& =0+A(\bar{A}+\bar{B})=\mathrm{A} \overline{\mathrm{B}} \\
& A \oplus A \bar{B}=\bar{A} \cdot A \bar{B}+A \cdot \overline{\overline{A \bar{B}}} \\
& =0+A(\bar{A}+B)=\mathrm{AB} \\
& A \oplus \bar{A} B=\bar{A} \cdot \bar{A} B+A \cdot \overline{\bar{A} B} \\
& =0+A(A+\bar{B}) \\
& =\bar{A} B+A+A \bar{B}=\bar{A} B+A \\
& =\mathrm{A}+\mathrm{B} \\
& (A \oplus B) \cdot(A \oplus C) \\
& =(\bar{A} B+A \bar{B}) \cdot(\bar{A} C+A \bar{C}) \\
& =\overline{\mathrm{A}} \mathrm{BC}+\mathrm{A} \overline{\mathrm{B}} \overline{\mathrm{C}}
\end{aligned}
$$

So, we got the conclusion and rules for XOR Boolean algebra:

$X \oplus 0=X$

$X \oplus 1=\bar{X}$

$X \oplus X=0$

$X \oplus \bar{X}=1$

$\bar{X} \oplus \bar{X}=0$

$\bar{X} \oplus \bar{X}=X \oplus X$

$A \oplus A B=A \bar{B}$

$A \oplus A \bar{B}=A B$

$A \oplus \bar{A} B=A+B$

$$
(A \oplus B) \cdot(A \oplus C)=\bar{A} B C+A \bar{B} \bar{C}
$$

\section{Conclusion}

Implementing XOR-gate characteristics into the standard rules and laws of Boolean algebra, will create a specific Boolean algebra that uses XOR function. It gives another way of solving logic equations which are written or given in XOR logic operator. 


\section{Acknowledgement}

I wou ld like to thank my colleagues and students for the moments and memories while working as a lecturer in my university.

\section{References}

[1] Malvino, A.P, ElektronikaKomputer Digital, PenerbitErlangga, Jakarta, 1988.
[2] Mano, M.M., Computer System Architecture, $3^{\text {rd }}$ ed.,PNJ: Prentice Hall, 1992.

[3] Tokheim, R.L.,Prinsip-Prinsip Digital,PenerbitErlangga, Jakarta, 1996.

[4] CIMT-Centre for Innovation in Mathematics Teaching, Boolean Algebra, University of Plymouth, 2005. Available: http://www.cimt.plymouth.ac.uk/projects/mepres/alevel/discrete_c h11.pdf.

[5] Katzen, S.J., EEE111J2 Digital Systems: Boolean Algebra and Karnaugh Maps, University of Ulster, Ireland, 2007. Available: http://katzen.me.uk/Books/sidssite/eee111a/digital_4.pdf. 